\section{Tos convulsiva epidémica y cambios en los esquemas de vacunación. Chile, 2012: ¿algunas interrogantes?}

\author{
Pertussis epidemics and changes in the \\ immunization schedules. Chile, 2012: \\ unanswered questions?
}

\section{Sr. Editor:}

La lectura del reciente e interesante articulo de Potin et al., refrendando la modificación del esquema de vacunación anti tos convulsiva en Chile para responder al parecer a la epidemia actualmente en curso, me ha planteado interrogantes que me gustaría dirigir a los responsables de estas decisiones y a los autores del artículo ${ }^{1}$. En primer lugar, como los autores lo discuten, aproximadamente la mitad de los casos de coqueluche epidémica se estarían presentando en la Región del Bío Bío y otras regiones, lo que apuntaría a que este incremento se debería a la presencia de factores locales que influencian negativamente la epidemiología de la enfermedad, específicamente en esas regiones. Factores locales que debieran ser identificables con estudios epidemiológicos y de laboratorio, incluyendo la pesquisa de anticuerpos relacionados con inmunidad a esta enfermedad, el cultivo y la detección molecular de Bordetella pertussis y $B$. parapertussis en enfermos y portadores y la caracterización fenotípica y genotípica de estos aislados ${ }^{2,3}$.

Por ejemplo, ¿cuál es la cobertura de la vacunación en la Región del Bío Bío y otras? ¿Podría deberse este aumento epidémico de la coqueluche en estas regiones a una falta de cobertura post terremoto o estar relacionada a factores socio económicos como pobreza y hacinamiento y bajos niveles de atención médica, ya que como los autores indican la cobertura general en Chile a los 2 años de edad es menos que ideal?' ¿Podría esto deberse a la presencia de variantes de $B$. pertussis con aumentado poder toxigénico o con variantes antigénicas de la hemaglutinina, fimbria o la pertactina? ${ }^{4,5}$ ¿O al uso de partidas de vacunas de diferente efectividad que en el resto del país o a un aumento en la notificación de la enfermedad? ¿Están siendo llevados a cabo estos estudios o existe alguna razón por la cual ellos a pesar de ser relevantes no se han realizado? En breve, la re emergencia de la coqueluche en Chile a diferencia de lo que sucede en Australia, E.U.A. y otros países, no se debe al uso de las vacunas acelulares de menor efectividad ${ }^{3}$, sino que a factores alternativos y propios del país, que debieran ser identificados ${ }^{6-10}$.

La literatura médica indica que la inmunidad antipertussis conferida por la vacuna celular es, en general, más efectiva que la conferida por las vacunas acelulares y que esta sería también de más prolongada duración, 4 a 12 años versus 6 años o menos ${ }^{2,6-10}$. Por ejemplo, se ha encontrado recientemente en California que la inmunidad conferida por cinco dosis de una vacuna acelular comienza ya a desaparecer el primer año después de administrada la quinta dosis ${ }^{10}$ y en Australia niños inmunizados primariamente con una vacuna de células enteras tienen un riesgo menor de desarrollar coqueluche que niños vacunados primariamente con vacunas acelulares ${ }^{6}$. A la luz de esta información pareciera que el cambio del segundo refuerzo con la vacuna DTP celular a los cuatro años por un refuerzo con la vacuna DT pertussis acelular en el primer año de enseñanza básica carecería de un fundamento claro. Esto, porque se remplazaría a una vacunación de superior efectividad, de inmunidad más duradera y más barata a los cuatro años, por una a los seis o siete años de menor efectividad, que confiere inmunidad al parecer de corta duración y más cara ${ }^{2,6-10}$.

Desgraciadamente en el artículo no se indica cuántos y cuáles antígenos contendrá la vacuna acelular que se usaría en Chile lo que permitiría evaluar mejor su potencial efectividad comparada con la celular, porque solamente vacuna acelulares de cinco componentes parecieran generar una inmunidad comparable a la vacuna de células enteras ${ }^{11}$. Con el conocimiento actual se puede perfectamente plantear que este cambio puede generar un intervalo de inmunidad disminuida antes de los trece años que es cuando se planea efectuar una inmunización con la vacuna acelular en adolescentes, y que esta inmunidad disminuida aumentará la circulación de la bacteria en la población, ampliando con esto las posibilidades de

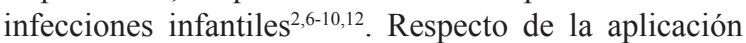
del principio precautorio para evitar la exposición de niños al timerosal presente en las vacunas de células enteras, este principio también debería considerarse en la introducción de la vacuna acelular ya que esta introducción ha ido acompañada de aumentos de la morbilidad y mortalidad por tos convulsiva en los países que la han introducido ${ }^{2,3,6-10}$. Parecería paradojal que mientras que en los países industrializados se le asigne al uso de las vacunas acelulares responsabilidad en la resurgencia de la tos convulsiva, en Chile se decida introducirlas al programa de vacunación infantil sin identificar previamente las causas de la resurgencia de la coqueluche en este grupo etario y sin que al parecer existan antecedentes de fenómenos reactogénicos inusuales con la vacuna de células enteras ${ }^{1,2,6-11}$.

Es indudable que en los diseños de planes de inmunización, además de los parámetros científicos y técnicos existen factores éticos, sociales y económicos que influencian estas determinaciones y esto está ilustrado meridianamente por la historia de la vacunación contra la tos convulsiva. A pesar de la carencia de información que 
demostrara que la barata y efectiva vacuna celular contra pertussis produjera grave morbilidad o aun mortalidad ${ }^{2,3}$, ella fue remplazada en los países industrializados por vacunas acelulares recombinantes de menor efectividad y $\operatorname{caras}^{2,3}$ Esto fue posible en parte por una inadecuada educación de la población respecto de los riesgos vacunales, por una prensa alarmista que establecía relaciones de causa efecto basada solamente en correlaciones, por el errado y el dogmático concepto de que lo técnicamente novedoso es mejor y por la influencia de los laboratorios productores de vacunas acelulares recombinantes que se beneficiarían económicamente con este cambio ${ }^{2,3}$.

En la vacunación para la coqueluche pareciera ser que en los países industrializados se reemplazó la prevención de potenciales graves efectos colaterales de la vacuna celular, por la morbilidad y aun por la mortalidad por coqueluche, generada por la falta de efectividad de las vacunas acelulares ${ }^{2,3,13}$. Esto ha creado a mi juicio una encrucijada sanitaria y ética de ardua justificación y de difícil solución, en un grupo de la población éticamente vulnerable ${ }^{14}$. En Chile, debido al potencial aumento de la coqueluche que este cambio en los programas de inmunización puede producir, él debiera ser precedido y basado en el análisis y la discusión amplia de investigaciones epidemiológicas, microbiológicas e inmunológicas con herramientas existentes, que diagnostiquen certeramente las causas de estos aumentos de la enfermedad en la población infantil del país. La carencia de estos estudios para justificar este cambio también introduce a mi juicio vertientes e interrogantes éticas que necesitarían de esta información técnica para ser resueltas en forma adecuada y equitativa.

\section{Referencias bibliográficas}

1.- Potin M, Cerda J, Contreras L, Muñoz A, Ripoll E, Vergara R. Modificación en el esquema de vacunación antipertussis en Chile, vacunación en grupos especiales y estrategias de control. Comentario del Comité Consultivo de Inmunizaciones (CCI) de la Sociedad Chilena de Infectología. Rev Chilena Infectol 2012; 29: 307-11.

2.- Mattoo S, Cherry J D. Molecular pathogenesis, epidemiology, and clinical manifestations of respiratory infections due to Bordetella pertussis and other Bordetella subspecies. Clin Microbiol Rev 2005; 18: 326-82.
3.- Cherry J D. The present and future control of pertussis. Clin Infect Dis 2010; 51: 663-7.

4.- Octavia S, Sintchenko V, Gilbert G L, Lawrence A, Keil A D, Hogg G, et al. Newly emerging clones of Bortelella pertussis carrying prn 2 and $p t x P 3$ alleles implicated in Australian pertussis epidemic in 2008-2010. J Infect Dis 2012; 205: 1220-4.

5.- Mooi F R, van Loo I H M, van Gent M, He Q, Bart M J, Heuvelman K J, et al. Bordetella pertussis strains with increased toxin production associated with pertussis resurgence. Emerg Infect Dis 2009; 15: 1206-13.

6.- Sheridan S L, Ware R S, Grimwood K, Lambert S B. Number and order of whole cell pertussis vaccines in infancy and disease protection. JAMA 2012; 308: 454-6.

7.- Cherry J D. Why do pertussis vaccines fail? Pediatrics 2012; 129: 968-70.

8. World Health Organization. Organisation Mondiale de la Santé. Weekly epidemiological record. [Relevé épidémiologique hebdomadaire]. $1^{\text {st }}$ October 2010, $85^{\text {th }}$ Year [1er Octobre 2010, 85 Annee]. 2010; 85: 385-400. http:// www.who.int/wer

9.- Wood N, McIntyre P. Pertussis: review of epidemiology, diagnosis, management and prevention. Paediatr Respirat Rev 2008; 9: 201-12.

10. Klein N P, Barlett J, Rowhani-Rahbar A, Fireman B, Baxter R. Waning protection after fifth dose of acellular pertussis vaccine in children. N Engl J Med 2012; 367: 1012-9.

11.- Zhang L, Prietsch S O M, Axelsson I, Halperin S A. Acellular vaccines for preventing whooping cough in children. Cochrane Database of Systematic Reviews 2011; Issue 1. Art. No.: CD001478. DOI:10.1002/14651858. CD001478.pub5.

12.- Ministerio de Salud amplió la vacunación contra el coqueluche a adolescentes de 13 años. http://www.ispch.cl/ noticia/ 15868

13.- Cherry J D. Epidemic pertussis in 2012-The resurgence of a vaccine-preventable disease. N Engl J Med 2012; 367 : 785-7.

14.- Cabello F. Experimentación en humanos y derechos humanos. ¿Está permitida la experimentación biomédica con niños? Rev Med Chile 1986; 114: 57-60.

Felipe C. Cabello Department of Microbiology and Immunology, New York Medical College, Valhalla, NY 10595, EE.UU. E-mail:cabello@nymc.edu 